\title{
Ethnography Without Tears
}

\section{Citation}

Roth, Paul A., Michal Buchowski, James Clifford, Michael Herzfeld, P. Steven Sangren, David Sapire, Marilyn Strathern, and Stephen A. Tyler. 1989. "Ethnography Without Tears [with Comments and Reply]." Current Anthropology 30, no. 5 (December 1989): 555-69.

\section{Permanent link}

http://nrs.harvard.edu/urn-3:HUL.InstRepos:34353685

\section{Terms of Use}

This article was downloaded from Harvard University's DASH repository, and is made available under the terms and conditions applicable to Other Posted Material, as set forth at http:// nrs.harvard.edu/urn-3:HUL.InstRepos:dash.current.terms-of-use\#LAA

\section{Share Your Story}

The Harvard community has made this article openly available.

Please share how this access benefits you. Submit a story.

\section{Accessibility}




\section{Ethnography Without Tears [with Comments and Reply]}

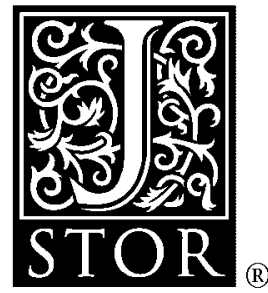

Paul A. Roth; Michal Buchowski; James Clifford; Michael Herzfeld; P. Steven Sangren; David Sapire; Marilyn Strathern; Stephen A. Tyler

Current Anthropology, Vol. 30, No. 5. (Dec., 1989), pp. 555-569.

Stable URL:

http://links.jstor.org/sici?sici=0011-3204\%28198912\%2930\%3A5\%3C555\%3AEWT\%5BCA\%3E2.0.CO\%3B2-J

Current Anthropology is currently published by The University of Chicago Press.

Your use of the JSTOR archive indicates your acceptance of JSTOR's Terms and Conditions of Use, available at http://www.jstor.org/about/terms.html. JSTOR's Terms and Conditions of Use provides, in part, that unless you have obtained prior permission, you may not download an entire issue of a journal or multiple copies of articles, and you may use content in the JSTOR archive only for your personal, non-commercial use.

Please contact the publisher regarding any further use of this work. Publisher contact information may be obtained at http://www.jstor.org/journals/ucpress.html.

Each copy of any part of a JSTOR transmission must contain the same copyright notice that appears on the screen or printed page of such transmission.

JSTOR is an independent not-for-profit organization dedicated to creating and preserving a digital archive of scholarly journals. For more information regarding JSTOR, please contact support @jstor.org. 


\section{Ethnography without Tears $^{1}$}

\section{by Paul A. Roth}

Critiques of ethnographic texts based on analysis of their rhetoric attribute epistemological significance to the literary devices used to represent oneself and others. In particular, rhetorical devices, and especially those that obscure authorial invention, are taken to be constitutive of a text's authority, i.e., the basis for warranting claims. I argue that the literary analysis of authority confuses literary, epistemological, and political issues.

PAUl A. ROTh is Associate Professor of Philosophy at the University of Missouri-St. Louis (St. Louis, Mo. 63 I 2 I-4499, U.S.A.). Born in 1948, he was educated at Wesleyan University (B.A., I970) and at the University of Chicago (M.A., I972; Ph.D., I978). His research interests are philosophy and social science, explanation, and ethics. He has published Meaning and Method in the Social Sciences (Ithaca: Cornell University Press, I987), "Narrative Explanation: The Case of History" (History and Theory, I988), "How Narratives Explain" (Social Research, in press), and "Deconstructing Quarks: Rethinking Sociological Constructions of Science" (Social Studies of Science, in press). The present paper was submitted in final form 8 III 89 .

I. Versions of this paper were presented to sessions on explanation in social science at the American Association for the Advancement of Science meeting in Wichita, Kans., in March I988 and at the Western Social Science Association meeting in Denver, Colo., in April of that year. I thank Stuart Plattner, Ray Scupin, John Bing, Robert Feleppa, Steve Fuller, Steve Woolgar, and Ray Senuk for their help and comments.
We have met the Unreliable Narrator ... and He is Us. CLIFFORD GEERTZ

Ethnographies are the stuff of which anthropological knowledge is made. Yet ethnographic data are invariably and inevitably "doubly mediated" (Rabinow I977:I I9) by anthropologists' preconceptions and those of their subjects of study. Given this double mediation, what counts as a reliable representation of experiences and cultures remote from one's own?

When, in "Understanding a Primitive Society," Winch (1970) argued that Evans-Pritchard had mischaracterized Azande reasoning by subjecting it to the standards of Western science, he provoked a long debate on the attribution of rationality (see Winch 1977; Hollis and Lukes 1982; Roth 1987:chap. 9). Implicated in this dispute was whether to privilege Western scientific thought, with one's answer to this question determining how others were to be understood. Recent writings suggest, however, that Winch mislocated the source of distortion of our understanding of others-that the problem of anthropological knowledge originates rather in the process by which ethnographic data are constituted as such, viz., in the writing of ethnographies (see esp. Clifford 1983, 1988; Clifford and Marcus 1986; Marcus and Cushman I982; Boon 1980; and, for a critical yet sympathetic assessment, Strathern I987). The charge is that the experiences inherent in fieldwork and in the writing of an ethnographic text deny validity to the conventional pose of detached observer-the "disappearance" of the ethnographer as explicit actor in and active author of reports on others. The problem of anthropological knowledge, according to these critics, is accurately reflecting the dynamic and interactive processes involved in presenting (or representing) ethnographic data.

Authority is taken to accrue not, as before, from the role of field scientist but rather from that of author. ${ }^{2}$ This focus on the ethnographer as author identifies the warrant for ethnographic claims with the position as narrator assumed by their author. My complaint is that this union of epistemology and literary criticism spawns no epistemological insights.

\section{Self-Presentation and Authority}

According to the new critique, the stylistic conventions of the traditional ethnography conceal the position of

2. I do not assume that the writers I discuss are of a single mind. A key common denominator, for my purposes, is the epistemological significance that all attach to literary convention and style /Clifford I986a:2): "[Contributors to Writing Culture] assume that academic and literary genres interpenetrate and that the writing of cultural descriptions is properly experimental and ethical. Their focus on text making and rhetoric serves to highlight the constructed, artificial nature of cultural accounts. It undermines overly transparent modes of authority.... Most of the essays, while focusing on textual practices, reach beyond texts to contexts of power, resistance, institutional constraint, and innovation." Even among those sharing this assumption, however, there is great diversity. 
the author and so falsely depict the author's role. Since these conventions are taken to be crucial to establishing the authority-the plausibility and legitimacy-of the text in question, revealing that they misrepresent has the effect of discrediting it.

The history of ethnography, as the new critics reconstruct it, is one of successive constitution and dissolution of "modes of ethnographic authority." Clifford (I983:I4I-42) identifies three such paradigms: the scientific participant-observer model pioneered by Malinowski, the hermeneutic/interpretive model whose most celebrated practitioner is Clifford Geertz, and a new discursive or dialogic model represented by, among others, Rosaldo's (I984) "Grief and a Headhunter's Rage" and Rabinow's (1977) Reflections on Fieldwork in Morocco. Malinowski created an image of the fieldworker as a kind of scientist and of ethnography as like the report of an extended experiment. Geertz rang a change on this model only to the extent that he approached his subjects of study without obvious commitment to any general theory of cultural functioning. He emphasized the way in which particular events, e.g., cockfights and sheep thefts, expressed a sense of self and of society. The privileged perspective now was not that of the scientist but that of the native (Geertz I979a). Both of these paradigms, according to Clifford, are subverted by the literary forms used to convey their purported insights (1986b:109):

Anthropological fieldwork has been represented as both a scientific "laboratory" and a personal "rite of passage." The two metaphors capture nicely the discipline's impossible attempt to fuse objective and subjective practices. Until recently, this impossibility was masked by marginalizing the intersubjective foundations of fieldwork, by excluding them from serious ethnographic texts.... This poses fundamental problems for any science that moves predominantly from the particular to the general, that can make use of personal truths only as examples of typical phenomena or as exceptions to collective patterns.

Ethnographies work against themselves in that establishing the fieldworker's credentials as an empirical scientist requires depicting a passive observer existing nowhere in reality. They are rendered unbelievable by the impossibility of this authorial pose.

This criticism, far from being limited to those who, like Malinowski, Firth, or Evans-Pritchard, imagined themselves to enjoy scientific detachment, is extended equally to the interpretive paradigm (Crapanzano I986: 74; see also Clifford I983:133-34):

there is in fact in "Deep Play" [Geertz I979b] no understanding of the native from the native's point of view. There is only the constructed understanding of the constructed native's constructed point of view. Geertz offers no specifiable evidence for his attributions of intention, his assertions of subjectivity, his declarations of experience. His constructions of con- structions of constructions appear to be little more than projections, or at least blurrings, of his point of view, his subjectivity, with that of the native, or more accurately, of the constructed native.

The examination of such ethnographic writing reveals, often enough, that putative reports of native doings are mere constructions of beleaguered ethnographers.

To restore authority to ethnographic reports, ethnographers must record the conditions of their creation. The new discursive paradigm licenses the "evocative, performative elements of ethnography" (Clifford 1986b:74), i.e., those focusing on the interplay between ethnographer and those studied. Concern for authenticity of voice replaces worries about standards of rationality (Clifford I983:133):

Henceforth, neither the experience nor the interpretive activity of the scientific researcher can be considered innocent. It becomes necessary to conceive ethnography, not as the experience and interpretation of a circumscribed "other" reality, but rather as a constructive negotiation involving at least two, and usually more, conscious politically significant subjects. Paradigms of experience and interpretation are yielding to paradigms of discourse, of dialogue and polyphony.

Accordingly, the ideal of the dialogic paradigm is realized when the voice of the writer is not (too obviously, anyway) a proxy for that of those studied.

For this new ethnography the construction of texts is the chief concern. "No longer a marginal, or occulted, dimension, writing has emerged as central to what anthropologists do both in the field and thereafter" (Clifford I $986 a: 2$ ). The new problematic consequently employs the devices of linguistic and literary analysis of narrative voice or positioning (see Martin I986:chap. 6). In this new paradigm "the dominant metaphors for ethnography shift ... toward expressive speech (and gesture). The writer's 'voice' pervades and situates the analysis, and objective distancing rhetoric is renounced" (Clifford I986a:I2). Culture is not passively apprehended but constructed through dialogue and negotiation.

In "Grief and a Headhunter's Rage," an exercise in the new author-centered ethnography, Rosaldo (I984) describes how initially he had taken as a problem his Ilongot informant's explanation of headhunting by griefinduced rage but later, having experienced the emotional turmoil consequent on his wife's death, realized that the Ilongot's account needed no supplementation. Comprehending their rationale for headhunting was not a matter of gathering additional data about them or of hermeneutic reflection on headhunting but a matter of having the relevant life experience. New experiences "reposition" the ethnographer. ("The concept of position refers to a structural location from which one has a particular angle of vision" [p. I93].) Here Rosaldo was repositioned relative to his assumption that he knew better than the Ilongot what needed explaining. Once 
repositioned, he understood himself as having just one perspective on their doings, and not a privileged one at that. More generally, the sort of person the ethnographer is requires scrutiny before crediting what the ethnographer says.

The assumption in all this is that conventions emphasizing the sensitivity of the investigator serve as a litmus test for the authenticity of the account. Foregrounding one's position, as in Rosaldo's account and the following one by Danforth (1982:5-7), somehow validates a study:

The maintenance of . . . ethnographic distance has resulted in ... the parochialization or folklorization of the anthropological inquiry into death. Rather than confronting the universal significance of death, anthropologists have often trivialized death by concerning themselves with the exotic, curious, and at times violent ritual practices that accompany death in many societies . . . . If, however, it is possible to reduce the distance between the anthropologist and the Other, to bridge the gap between "us" and "them," then the goal of a truly humanistic anthropology can be achieved....

... As I sat by the body of a man who had died several hours earlier and listened to his wife, his sisters, and his daughters lament his death, I imagined these rites being performed and these laments being sung at the death of my relatives, at my own death. ... When the brother of the deceased entered the room, the women ... began to sing a lament about two brothers who were violently separated as they sat clinging to each other in the branches of a tree that was being swept away by a raging torrent. I thought of my own brother and cried. The distance between Self and Other had grown small indeed.

The tears here fill the cultural space between Self and Other. The author, having exposed himself, is now certified to expose others. As Geertz (I988:99) observes with regard to related writings, "The sincerity crux awaits all who pass this way."

The new critique takes issue with ethnographers' representations of self, only rarely (though Marcus I986 is an exception) with their specific theoretical assumptions. Analysis characteristically focuses on a text's style as essential to what makes it convincing (Marcus and Cushman 1982:38-39):

Authority is the combined structure of a covering legitimation and the styles of evidence derived from it for the page-by-page descriptions and claims of a text. This structure, integral to the text, should constantly reinforce unselfconsciously the reader's confidence in the author's knowledge as sufficient credibility for what the text states. ... Careful attention by readers should be given to the various ways in which marks of enunciation (i.e. the authorial first person), fables of rapport in the field, and more generally, the representation of fieldwork experience are written into the text, precisely because they consti- tute the basic rhetoric of authority which legitimates whatever is said and claimed about "the other."

Authorial voice is deemed integral to the "proof" a text provides (see, e.g., Clifford's [1983:I30] analysis of The Nuer). The authority imputed to certain ethnographies is then called into question by revealing the implications of certain grammatical devices that they employ-for example, third-person constructions that imply an acquaintance with the thoughts of others that the ethnographic author cannot have. Again, it is not the theory of the culture that is judged inadequate in some specified way but the picture of the position from which the ethnographer portrays it. The model for thinking about an ethnography in this way is, of course, the critical assessment of a work of fiction. That is, once the assumption is made that ethnography is not a science, scientific standards are no longer essential even to the critique of ethnography.

Clifford, indeed, examines questions of narrator and audience, of how a persona is fashioned, in Conrad's Heart of Darkness and Malinowski's Argonauts of the Western Pacific as fundamentally of a kind. "Argonauts is less reflexive, but it does both produce a cultural fiction and announce the emergence of an authoritative persona: Bronislaw Malinowski, new-style anthropologist. ... The persona does not represent but rationalizes a research experience" (I988: I IO; see also 4I). His position implies that our reasons for considering the narrator of Argonauts reliable are fundamentally akin to those for so considering Marlow. No distinction is drawn, in this regard, between fiction and nonfiction. Absent, ironically, from his account is what makes a claim to authority socially acceptable-which rationalizations pass social muster and why. ${ }^{3}$ Focus on conventions of authorial self-representation neither debunks a text nor explains its professional reception.

Ethnography thus reconceived makes self-conscious authorial positioning an authenticating device, a mode of legitimating claims to ethnographic authority (see Clifford 1980:529). Misrepresentation of self calls into question the credibility of the text as a whole. Selfconscious self-representation signals a reliable narrator and confers credibility on the text.

Clifford and fellow critics sometimes write as if they were advocating a mere plurality of forms, identifying additions to established conventions and canons, ${ }^{4}$ and

\footnotetext{
3. For a classic statement of a sociological movement dedicated to locating the acceptance of scientific texts within a specific web of social interests, see Barnes and Bloor (I982). Two of the more detailed case studies are those of Pickering (I984) and Forman (I97I); see Roth (1987:chaps. 7 and 8) for an evaluation of this view. 4. Clifford's target is often the presumption embodied in earlier ethnographies that it was possible to report "scientifically" or "objectively" on others. He rightly emphasizes the constructed and partial perspectives that these works offer (see, e.g., I988:Io and esp. 55-9I; 1983). His concern to debunk the scientific pretensions of ethnographic writing and to advocate a pluralist approach to modes of representation is to be admired and applauded (see Rabinow I 983 for a critical yet appreciative discussion of some of Clifford's work on these points and also Roth I987).
} 
sometimes suggest that earlier paradigms are to be replaced by the discursive/dialogic model (see esp. Crapanzano 1986, Fischer 1986). For example, Clifford says of the Malinowskian model that it "can now be identified as only one possible paradigm for authority," implying that it is nonetheless a viable option. More generally, he writes that the modes of authority he reviews "are available to all writers of ethnographic texts, Western and non-Western. None is obsolete, none pure: there is room for invention within each paradigm" (I983:I4I-42).

Yet he regularly identifies the misrepresentation of self as undermining the authority of older ethnographic models. For example, the Malinowskian model attempts to meld the personal and the scientific; it demands that the fieldworker live among natives and yet be a detached observer of them. This requirement, Clifford insists, represents an "impossible attempt to fuse objective and subjective practices" (I986b:I09). In contrast, "the new tendency to name and quote informants more fully and to introduce personal elements into the text is altering ethnography's discursive strategy and mode of authority. Much of our knowledge about other cultures must now be seen as contingent, the problematic outcome of intersubjective dialogue, translation, and projection." The discursive paradigm's greater appropriateness, in turn, is a function of its acknowledging the fragmentary nature of the evidence on which the ethnographer's authority rests. As Strathern (I987:264) remarks, Clifford's work is intended as an exposé of "the figure of the fieldworker who was the register of the otherness of cultures. Clifford tackles the authority which anthropologists claimed this gave their writings: the fieldworker who came back from another society spoke for it in a determining way which now appears repugnant." No single voice articulates any mythical cultural consensus.

Within a paragraph of having stigmatized nondialogic accounts, however, Clifford proceeds to resuscitate them: "these accounts are clearly no longer the story, but a story among other stories" (I986b: I09). Viewed as one possible mode of interpretation, nondiscursive accounts are acceptable. But if the authority of a paradigm is a function of the way in which the author is conventionally presented, then this ready redemption of the Malinowskian paradigm should not be possible. ${ }^{5}$ It is one thing to stress how field data may be read to different effects, for example, contrasting Evans-Pritchard's travails among the Nuer with his detached style, and quite another to maintain that some one reading is better than others. The following passage from Clifford (I983:I I9, emphasis mine) shows how these issues are conflated in his writings:

After the Negritude movement's reversal of the European gaze, after anthropology's crise de conscience with respect to its liberal status within the imperial

5. I am not alone in noting this; see especially Rabinow (I986), who, however, shrugs it off: "At first I thought this was mere inconsistency, or ambivalence, or the embodiment of an unresolved but creative tension. I now think that Clifford, like everyone else, is 'dans le vrai'" (p. 247). order, and now that the West can no longer present itself as the unique purveyor of anthropological knowledge about others, it has become necessary to imagine a world of generalized ethnography. With expanded communication and intercultural influence, people interpret others, and themselves, in a bewildering diversity of idioms-a global condition of what Bakhtin called "heteroglossia." This ambiguous, multi-vocal world makes it increasingly hard to conceive of human diversity as inscribed in bounded, independent cultures. Difference is an effect of inventive syncretism. In recent years works like Edward Said's Orientalism and Paulin Hountondji's Sur la "philosophie africaine" have cast radical doubt on the procedures by which alien human groups can be represented, without proposing systematic, sharply new methods or epistemologies. These studies suggest that while ethnographic writing cannot entirely escape reductionist use of dichotomies and essences, it can at least struggle self-consciously to avoid portraying abstract, a-historical "others." It is more than ever crucial for different peoples to form complex concrete images of one another, as well as of the relationships of knowledge and power that connect them. But no sovereign scientific method or ethical stance can guarantee the truth of such images. They are constituted - the critique of colonial modes of representation has shown at least this much-in specific historical relations of dominance and dialogue.

Here, in successive sentences, Clifford simply contradicts himself. He confidently declares (I) that no method guarantees the truth of statements regarding the forces shaping people's relations to one another and then-making the kind of methodological claim that he has just rejected-(2) that such relations can be understood "in specific historical relations of dominance and dialogue." ${ }^{\prime 6}$

Writing in his pluralist mode (recognizing that there are only partial truths), Clifford (I988: I I 2; see also 60) argues that "fieldwork-based anthropology, in constituting its authority, constructs and reconstructs coherent cultural others and interpreting selves. If this ethnographic self-fashioning presupposes lies of omission and of rhetoric, it also makes possible the telling of powerful truths." Elsewhere, however, his language suggests the impropriety of nondialogic modes (p. 4I):

Geertz's abrupt disappearance into his rapport-the quasi-invisibility of participant observation-is paradigmatic. Here he makes use of an established convention for staging the attainment of authority. As a result, we are seldom made aware of the fact that an essential part of the cockfight's construction is

6. Robert Feleppa has objected that I impute an unduly rigid position to Clifford: that the first sentence here means to do no more than to assert the legitimacy of pluralism and the second to suggest that, since no method can be considered the "sovereign scientific method," dialogic and other literary approaches must be taken seriously as well. In the context of Clifford's general critique, however, this charitable reading simply does not fit. 
dialogical-the author talking face to face with particular Balinese rather than reading culture "over the[ir] shoulder."

In this he no longer countenances "partial truths" but stresses rather that Geertz obscures and omits an "essential part" of the tale he tells. Since this obscurity is also identified as an element of the text's authority, presumably exposing the device undercuts that claim. Finally, in still another context he writes as if he believed that only a dialogic representation of ethnographic experience is authentic or legitimate (p. 90):

initiatory claims to speak as a knowledgeable insider revealing essential cultural truths are no longer credible. Fieldwork cannot appear primarily as a cumulative process of gathering "experience" or of a cultural "learning" by an autonomous subject. It must rather be seen as a historically contingent, unruly dialogical encounter involving to some degree both conflict and collaboration in the production of texts.

Since Clifford has identified authorial pose or selfpresentation as a basis of textual authority, of course misrepresentation of that position must be deemed significant. Insofar as he elsewhere acknowledges that an ethnographic text's authority depends on factors independent of authorial self-presentation, he can be a pluralist. But his pluralism comes only at the price of denying epistemological relevance to his literary analysis of voice. Since we are all unreliable narrators, making sense where and as we can of life's "dada data," and since the "telling of powerful truths" becomes possible precisely by favoring a perspective, critiques of knowledge need to emanate from some other line of analysis.

\section{Self-Awareness vs. Self-Criticism}

While certainly Clifford is right to maintain that social reality is a "constructive negotiation" (I988:4I), just as surely it is wrong to claim that merely indicating the conventions of ethnography reveals which conventions are worth challenging. ${ }^{7}$ As Boon (I 982:263 n.2) observes,

Experimental ethnographies often try to burst the shackles of old-fashioned, establishment description, often by merely stressing rather than disguising a first-person pronoun. It would seem more pertinent to find a way to reveal the intense conventionality of standard ethnography ..., to engage in a reflexivity that ushers rival formats into critical self-consciousness.

Stressing the position of the author is not a sufficient condition for a critical reflexive self-consciousness, since, as Boon notes with regard to functionalist methods, once "this preconception is duly acknowledged, there is nothing wrong with it."

7. Sangren (I988:4I6) makes just this point: "to discover ideology in texts, however, does not mean that the arguments that they embody are incorrect."
Against Geertz's (I988:9I-IOI) questioning of the benefit of spiraling self-consciousness in ethnography, Clifford (I988:113) celebrates such models, implying that this type of self-display counts as theoretical critique:

In recent years new forms of ethnographic realism have emerged, more dialogical and open-ended in narrative style. Self and other, culture and its interpreters, appear less confident entities. ... The experimentalists reveal in their writings an acute sense of the fashioned, contingent status of all cultural descriptions (and of all cultural describers).

One may respond here, as Boon does in another context, that "when everything starts sounding emancipatory" one senses "Enlightenment prejudices . . . creeping uncritically back in" (Boon I982:266 n. I4). Clifford suggests that tortured self-consciousness regarding the social construction of knowledge is somehow emancipatory, but we await any demonstration that such accounts reveal much beyond the ambivalences of their authors.

Clifford's notion of "ethnographic surrealism" contrasts sharply with that represented by the experiments in the social construction of knowledge pioneered by Garfinkel (1967) and developed in recent work by Woolgar (I988; Latour and Woolgar I986), apparently entailing no more than that the "cuts and sutures of the research process are left visible" (I988: I46). "Ethnography as collage would leave manifest the constructivist procedures of ethnographic knowledge; it would be an assemblage of voices other than the ethnographer's, as well as examples of 'found' evidence, data not fully integrated within the work's governing interpretation" (p. I47). On a more methodologically sophisticated view of the construction of knowledge, Clifford's dialogic paradigm is not constructivist simply because it is not critical or revealing of what dialogic processes presuppose. Griaule's work, as Clifford characterizes it, is in fact more reflexive than the dialogic models. For example, Clifford points out that Griaule consistently tricks his informants into revealing unstated views or intrudes in purposefully disruptive ways in their ceremonies. Readers of Studies in Ethnomethodology (Garfinkel 1967) or Laboratory Life (Latour and Woolgar I986) will find similar sorts of tactics being employed. Reflexive research reveals by provocation of the taken-for-granted. As Clifford says of Griaule, "to an important degree the truth he recorded was a truth provoked by ethnography" (p. 77). The truths revealed by reflexive sociology or anthropology remain historically situated constructs, but they reveal what is often implicit in social interactions.

Heteroglossia does not guarantee authenticity or insight; it is largely beside the epistemological point. If the goal is representation in some political sense, then of course it has merit, but there is no necessary connection between political representativeness and methodological fruitfulness or desirability. Texts failing to be representative in the former sense cannot, for this reason alone, be convicted of being misrepresentative in the 
latter. Indeed, one must allow for the possibility that some people, at least, have matters about themselves and their society wrong. The search for even interpretive truth is not a democratic process.

Clifford writes as if acknowledgment of political situatedness revealed all, but the sorry fact of the matter is that it provides no more determinate a basis for reconstructing knowledge and belief than the sense-data elements of traditional foundationalist epistemologies. Thus, one may grant "that the poetic and the political are inseparable" (I986a:2) yet question whether this insight yields any even partial truths. After the sophisticated literary analysis of voice is done, all the ordinary questions of method-for example, under what conditions the evidence cited supports a claim-remain.

Nondialogic models, granted, do not accurately portray the way in which the ethnographer is educated in the field, but whether this is significant depends on whether it entails some further misunderstandingwhether some claim made about the society is incorrect. For example, Evans-Pritchard's pose of detached observer does not prevent Clifford from judging The Nuer a classic; to misrepresent the enterprise is not necessarily to misrepresent the society. In this respect, even the rhetorical devices of the discursive paradigm are a sham (Marcus and Cushman 1982:48; see also 49):

Aside from preparing readers epistemologically for radical differences, self-reflection serves to sharpen the separation between the ethnographer and his representation of difference, thus achieving the effect that native worlds are authentically different. ... This is despite the fact that the textual representation of difference is squarely the constructive work of the ethnographer's writing practice. In this sense, epistemological self-reflection should be seen as only the most contemporary and sophisticated form of a rhetorical technique of comparative contrast that has long been employed in realist ethnographies.

Stylized self-reflection no more guarantees authenticity than does a pose of detachment.

\section{Epistemological vs. Political Representativeness}

What a discursive paradigm helps ensure, on reflection, is representativeness in a political sense-what one might call ethnographic democracy (Clifford I983:I3940; see also I34, I 35 and Tyler 1986:126, I29; Fischer I986:I94n):

Ethnographic discourses are not, in any event, the speeches of invented characters. Informants are specific individuals with real proper names-names to be cited, in altered form when tact requires. ... This suggests an alternate textual strategy, a utopia of plural authorship that accords to collaborators, not merely the status of independent enunciators, but that of writers. ... Anthropologists will increasingly have to share their texts, and sometimes their title pages, with those indigenous collaborators for whom the term "informants" is no longer adequate, if it ever was.

This ideal of ethnographic writing-a "utopia of plural authorship" - is a corrective to ethnographers' alleged insensitivity to their political relations with those they study (see, e.g., Asad I973:I6-I7, II4, II 8; and, for' a balanced statement, Maquet 1964:54). Polyphony recommends itself not because its epistemological virtues have ever been established but because it seems to absolve ethnographers of the sins of their past. Domination of ethnographers' voices in their texts is equated with colonialism (see Asad I973:16-17). The real sin of the nondiscursive paradigms is that they deny other voices: "The idea is to allow multiple sets of voices to speak for themselves ... in order, as Tzevtan Todorov puts it, to avoid 'the temptation to reproduce the voices of these figures "as they really are": to try to do away with my own presence ... [or] to subjugate the other to myself, to make him into a marionette" (Fischer 1986:200-201). The repeated theme of the essays in Writing Culture is precisely this concern with representations of others (individuals or cultures) as a form of domination (see esp. Tyler I983, Marcus I986). "The word tends to preserve a privileged authorial standpoint, as does 'interpretation'" (Clifford I980:529). This conception of representation, however laudable as a political goal, confuses hoped-for antidotes to colonialism with matters of warrant and proof.

\section{Summary}

Three confusions, then, may be identified in the new critique: (I) of writing style, especially self-presentation, in ethnography with the way in which claims are warranted, $(2)$ of self-awareness with self-criticism, identification of authorial position with reflexive analysis of shared assumptions, and (3) of political with epistemological representativeness. ${ }^{8}$ Because of this confusion,

8. These kinds of problems have been well-discussed with regard to similar analyses of natural science by Woolgar (I981 $a, b$, and esp. I983, to which my own analysis owes a great deal). For a cogent assessment of the epistemological problems of competing ethnographic paradigms, see Strathern 1987, Keesing 1987). Among the other problems with the new critique is its tendency to require fieldworkers, like Cromwell's portraitist, to show every wart; a map has its uses even if not every feature of the terrain is represented. As Strathern and others have noted, moreover, sometimes the partiality of a perspective is precisely what is illuminating. A feminist critique, for example, does not claim to address every point in a given text but to illuminate some of them (for a particularly interesting and insightful analysis of the rhetoric here, see Elshtain r 987). Clifford, in most of his moods, is alert to the value of "partial truths"; others seem to work with notions of meaning and authenticity that I have called "meaning realism" (Roth I987). There is, as well, a failure to appreciate the consequences of adopting, as these critics do, a holist position in epistemology; for a discussion of some of these, see Roth (1987) and Geertz (1980, 1985, and 1988:esp. chap. 6). 
tears come to be attributed epistemological significance. The problem is to avoid domination; authenticity of feeling solves this problem because it disavows a privileged position. Self and Other, even if they do not see eye to eye, relate in any case at eye level. On my reading, the charge of misrepresentation is plausible but epistemologically innocuous-plausible in that theoretical position is always partial and so politically misrepresentative, epistemologically innocuous since the charge of partiality applies to all positions. Most important, literary analyses of ethnographic texts, although they may document an interweaving of style and perspective (this is the virtue of Geertz I988), leave unanswered and untouched the epistemological questions with which this debate began, viz., how properly to warrant claims from within a chosen perspective and how to assess the political import of one's position.

\section{Comments}

\section{MICHAE BUCHOWSKI}

Institute of Ethnology, Adam Mickiewicz University, ul. Marchlewskiego I 24, 6I-874 Poznań, Poland. I VI 89

I am in a rather difficult position in commenting on Roth's paper for at least two reasons: First, I am not involved in the torrent of discussion on postmodernist anthropology in America, so I cannot directly "negotiate" $^{\prime \prime}$ all its different meanings. Second, I strongly agree not only with Roth's main thesis that all this talk about rhetoric in anthropology is epistemologically innocuous but also with many of the arguments that have led him to this conclusion. Because of this, my gloss could be entitled "A View from Afar."

It seems to me that the subjective, dialogical, discursive paradigm in anthropology is a reflection of a change in Western civilization, which has systematically been losing its belief in its own standards-the effect of increasing awareness of the plurality of cultures or lifestyles and the crisis of norms in modern societies. What is interesting, however, is that anthropology has contributed substantially to this growing social consciousness of pluralism and relativism, and, paradoxically, the methods of anthropological research (including ethnography) have been subverted in the process. Arguments about the subjectivity of ethnographic fieldwork and the relativity of anthropological theories have led many scholars to reject the methodological norms and directives of science and propagate a variety of hermeneutic methods. Postmodernism and the new critique of stylistic conventions are part of this trend. Negotiation of senses, feelings, common life experiences (such as Rosaldo's turmoil after his wife's death), discourse, polyphony, and concentration on rhetoric are supposed to provide an authentic picture of the situation (I do not venture to say the "real" situation). But if the an- thropologist's perception is unavoidably Western-bound, anthropology being a product of Western culture, then the postmodernist view is as ethnocentric as any other. Moreover, if we accept that no one can escape his cultural background, what is the point of pretending to do so-especially through claims about the role of writing style (mainly a technical question)? Adherents of hermeneutic methods seek salvation in subjectivitywhich apparently means renunciation of any kind of "objectivity." But if this is necessarily "our" vision, why should we discard such distinctive elements of it as the methods evolved in the scientific tradition?

Those who try to meet the demands of scientific reasoning respect certain standards that guarantee interpersonal communication. This perspective does not exclude local beliefs from anthropological activity and explanation. There is no reason not to incorporate the (native) "humanistic coefficient" of perceived actions and events, as Florian Znaniecki put it, into anthropological metalanguage. In other-perhaps postmodern-words, we negotiate meanings with natives (and this is a matter of fieldwork methods and ethnographic sensitivity) and then incorporate them into (scientific) descriptions and explanations that respect certain historically determined and changing methodological norms. This verification of meaning and sense is socially circumscribed, relative- "our objective knowledge" on a given topic. It is neither more nor less relative than hermeneutic activity, but it is verifiable. There is no need to take refuge in subjective, unrepeatable experience. In this regard, concentration on the writing of texts is a rhetorical device. The whole enterprise tends to become an art--literature based on anthropological themes-and no longer anthropology.

This does not mean that I deny the hermeneutic and postmodernist movement any importance. Anthropology from now on will be more conscious of its conventionality and its writing styles, and assessment of those claims of the movement that meet the above-mentioned standards of science and provide epistemological insights may make a real contribution to anthropological theory.

It is interesting that this is not the first time that American anthropological thought has given such close attention to the influence of language on world view (cf. the Sapir-Whorf theory). Finally, one might tentatively consider the whole postmodernist movement a "marketing" effort and a kind of struggle for succession in American departments of anthropology.

\section{JAMES CLIFFORD}

History of Consciousness, University of California, Santa Cruz, Calif. 95064, U.S.A. I9 vi 89

I must confess that I feel myself akin to the teenager Pratt (1986:30) invokes in Writing Culture-dragged into a strip joint by the authorities in order to be thrown out. I have never claimed to "authenticate" ethnography by focussing on the self, on sincere feelings, or even on 
the intercultural encounter. (Roth constructs a straw argument out of disparate, truncated quotations.) I have never argued that "literary" analysis of the rather conventional sort understood by Roth or discourse analysis in the Foucaultian tradition can provide conclusions about truth and misrepresentation. I have not made systematic "epistemological" claims and indeed reject the possibility of such claims for historicist and political reasons that Roth does not seriously confront.

One dismissive review of Writing Culture reduced the book's introduction to the claim that "all truths are partial," adding, "So what else is new?" Roth says something like this in his summary paragraph when he finds my approach "epistemologically innocuous since the charge of partiality applies to all positions." What is shrugged off in such comments-and this, to me, is the most troubling aspect of Roth's essay-is the historical and political specificity of the "partialities" in question. For example, Roth passes over the postcolonial context for many of the recent debates over ethnographic representation, a context featured throughout my work and that of writers like Rosaldo, Rabinow, Pratt, Fabian, and Asad, to name a few. And why is the discussion of feminist contestations of "epistemology" and "method" in my introduction to Writing Culture of no interest to him? I hope that Roth, in his response below, will justify his removal of historical and political content from arguments about validity, warrant, and proof. I hope that he will explain how he is able to keep "political" problems of representation and location so neatly separate from problems of "epistemology," especially in light of the continuing history of contested, revised, limited, recontextualized "truths" in Euro-American ethnography. And I hope that he will elaborate on the hints (in n. 4 and elsewhere) concerning his own "pluralist" vision. What does it systematically exclude? How does he conceive his own place of pluralist survey without recourse to the historical flying carpet on which my own work trips?

Roth misunderstands the "dialogical" approach by reducing it to a "new author-centered ethnography." (Of course, one can say something has been excluded, is important, is real, one can give it close attention, without claiming that it is the essential reality.) The point of dialogical awareness is to decenter the self, to focus neither on the (intimate) self nor on the (distanced) other but on the historically and politically constituted field of relationships between (and constituting) self and other. Moreover, Roth's reduction of the "new" ethnography to narrowly literary critiques of authorial position is a serious distortion of the role of "discursive" relations in constituting intercultural knowledges. To insist on pigeonholing the "new" ethnography as "literary" is to ignore all the explicit tensions and debates around this category in Writing Culture and elsewhere (e.g., Clifford I986a:3-8).

It may be worth dwelling a bit on one misunderstanding that Roth shares with other readers of some of my work. To assert as he does that my attention to authorial positioning, dialogue, and discursive struggle is part of a project "to restore authenticity to ethnographic reports" is an odd misreading, since virtually everything I have written in this area aims to show that any claim to authenticity must always be tactical, politically and historically contingent. Roth's feeling that I waver on this point derives, I suspect, primarily from my essay "On Ethnographic Authority" (I983). There I write that all the authorial paradigms I survey are going concerns, fraught with authority. At the same time, I clearly welcome the emergence of explicitly "dialogical," "discursive," and "polyphonic" textual strategies (not the same things, as Roth often assumes). Several readers have seen a contradiction or, charitably, a predicament (Rabinow I986:247) in my simultaneous acceptance of multiple strategies and my positive portrayal of certain emergent paradigms. Were I to rewrite the essay now, I would guard even more strongly against the assumption /which Roth shares) that my "ideal" paradigm is dialogical or polyphonic. Apparently it was not enough to stress the different limitations of each paradigm and to qualify the most radically polyphonic as "utopian." (I suspect that readers who have wanted me to say that "dialogic" and "polyphonic" approaches are really the best and most truthful approaches betray their own nostalgia for a single valid method in ethnography, the one best way to guarantee the truth of cultural representations.) In any event, my tactical preference for "discursive" paradigms (as opposed to visual, descriptive ones) is based on their ability to challenge and complicate dominant monological conventions in Western social science, not on their purported access to a privileged ethnographic truth. I had hoped that by reprinting "On Ethnographic Authority" (I988:2I-54) in close conjunction with essays on Griaule I 988[I983]:55-9I) and Conrad and Malinowski I988[I985]:92-II3) this would be all too clear. In the first of these "dialogic" relations are violent and anything but egalitarian; in the second, all ethnographic truths are based on exclusions.

Thus, if I have welcomed the emergence of new, or suppressed, textual forms it is because they help create a field of explicit contexts for authority, not because they guarantee a superior truth or a safe, guilt-free "method" for postcolonial cultural representations. My own hesitation to adopt a pluralist meta-position (the position Roth apparently prefers) has to do, as he observes, with a political commitment. This is a commitment not to a naive "democracy" of perspective but to an ongoing contestation of both the form and the content of powerful accounts of non-Western peoples and societies. In the historical context of postcolonialism (a loose but necessary periodization) and within the specified domain of a troubled Western social science, I have welcomed emergent paradigms of authority without according them the kind of "epistemological" or "methodological" primacy that many readers wanted. Thus what Roth can, in a forced reading (see n. 6), portray as a contradiction is a systematic ambivalence and complex location, an attempt to survey discrepant paradigms and to chart current contestations of authority from a politically and historically enmeshed position itself only partially 
understandable (because open-ended) and built on exclusions (see Clifford I986a:20 and chap. I; I988: I-20, 95, 275, 290; Gordon I988; Hooks I 988). This sort of positioned analysis does not yield the kinds of epistemological results Roth demands. It does perhaps have something to say about the geopolitical locations and historical contingency of ethnographic constructions. But that is another "epistemology."

\section{MICHAEL HERZFELD}

Department of Anthropology, Rawles Hall I08,

Indiana University, Bloomington, Ind. 47405, U.S.A. I 3 VI 89

Roth sees the ethnographer's tears (Danforth I982; Rosaldo I989:I-2I) as an abdication of epistemological responsibility. Were they offered in place of detailed ethnography, he might well be right. Not only does he indiscriminately cast all ethnographic lamenters into the same pit, however, but he ignores his own advice to evaluate each ethnography in its own context of production. Such evaluation must ultimately be a comparativist project. Thus, for example, Danforth describes a Greek village-in other words, not necessarily part of a "European" society but certainly a segment of a national entity whose own pretensions involve the ethnographer in difficult ideological questions of commonality vs. difference. True, the relationship between the ethnographer's cultural selfhood and the society's straddling of an imposed otherness may imply the risk of Euro-assimilationism, but the simultaneous recognition of otherness within such a community is a powerful antidote. Rosaldo (I980), conversely, shows us a society whose own complex history is no match for the appropriative national values of a Eurocentric state structure: a society whose fierce and now banished headhunting seems made for the manufacture of a binary opposition setting it against fictionally gentle Tasaday. Here, the recognition of common emotions stands clearly contrasted with the illiberal undercurrent of conventional cultural relativism ("separate but equal": cf. Dumont I 982:238-39; see also Fabian 1983). Yet here too, as Roth recognizes, any claim to ultimate hermeneutic authority would risk being even more insidious than those identified (e.g., Clifford and Marcus I986; Clifford I988: 2I-54) in earlier ethnographies.

Some modern ethnographies quite explicitly reject such claims. The discursive self-awareness they demand calls for a juxtaposition of readings that would place them in the historical contexts of essentialist debates about national identity, the meaning of culture, and the social and cultural conditions under which otherness gets constructed. Once ethnography has included in its purview both its own practices and those of national entities, Roth's pluralism in fact comes to resemble Rosaldo's (I 989) "multiple repositionings" quite closely. Both entail a "Saussurean" ethnographic principle that "A means B in the context of C" (Schwimmer I979:272-
73). In short, the epistemological sensitivity for which Roth is calling can only be realized if the project of the ethnographic analysis of what anthropologists do (not just the textual analysis of what "natives do," and here I agree with him) can be inserted into the wider comparativist project that makes anthropology what it is. And since what anthropologists do, mostly, is "write" (Boon I982), that means ethnographizing their texts rather than textualizing ethnography.

Back, now, to tears. The discipline has tried to erase universalism on the grounds that it violates authenticity (see Fabian 1983; Clifford I988:23I); Roth appears, plausibly, to wonder whether the rhetoric of sincerity may not be a means of covertly reintroducing it. Authenticity, always a constructed and reified property /see Handler I986), is as such always somewhat like the claims of nationalism. Calls for more authentic ethnography may thus seem to violate their own standards of decency. Pluralism may well be the least hegemonic stance available - the most empirical, as (diametrically) opposed to empiricist (see Herzfeld I 987:204; on a complexly heteroglossic pluralism, see Friedrich 1989). But then fuller awareness of alternatives might be bettermore empirically - achieved by once again emphasizing the close relationship between epistemological and nationalistic claims. Both are about "authenticity," and both begin from "revolutions" that too easily turn into repressive normativities. Knowing this, we can appreciate their beginnings and resist their self-serving pursuit of telos. Sunt lacrimae rerum: the recognition that tears inhere in all human experience begins, for both Danforth and Rosaldo, in direct particularistic ethnography. Why should such a commonality of experience not render alien representations of affect more accessible? As long as this does not then induce an unselfconscious slide into psychologism (see Needham I980), the sense of dialectic-of plurality at once cultural and epistemological - can be maintained. If Roth indeed wants to resist new hegemonies, new canonicities, then he is arguing on the critical anthropologists' own grounds and perhaps managing better than they sometimes do; but if he treats their textual practices as irrelevant to epistemology (itself seen as a segment of the ethnography of modern life), he is once again repeating the error with which they charge the ancestors and with which he charges them.

If anthropological comparativism is "impossible," as Evans-Pritchard is said to have remarked (Beidelman I980), is not this the very impossibility Roth finds in the epistemological dilemma? And is not our appreciation of this impossibility, common to the analysis of ethnographic "subjects" and ethnographers' own texts alike, what enables us to resist "final solutions" that are as perverse in anthropology as they are perverted in nationalism? The gain lies not in more effective "warrant and proof" but in making reflexivity an ethnographic rather than merely a contemplative project. This is what Winch (esp. I970:80-8I) began, haltingly, to articulate. In our day, we have fewer good (i.e., contextual) excuses for failing to pursue that challenge. 
P. STEVEN SANGREN

Department of Anthropology, McGraw Hall, Cornell

University, Ithaca, N.Y. I4853, U.S.A. I4 vi 89

I shall limit my comments to elaborating one of Roth's important points-that Clifford "confuses hoped-for antidotes to colonialism with matters of warrant and proof" and that this confusion is linked to his equating the construction of authorial voices in ethnography with political domination. Roth focuses on this confusion in the interest of revealing the dearth of substantive contribution to social theory in arguments like Clifford's that claim to constitute a critique of theory and scientific practices and propose normative standards for ethnographic endeavors. Roth implies that the appeal of such stances derives from the superficially "political" (as opposed to epistemological or methodological) claim to greater tolerance associated with sanctioning the incorporation of multiple voices into our ethnographic productions.

When one invokes "pluralism" as a legitimating value, one must be clear about context. In disputes like this one there seem to be two analytically distinct but associated contexts in which the value of a plurality of voices ought to be defended. First, as Clifford emphasizes, it is important to defend expression of the voices (and the rights) of the politically and economically dominated (including but not limited to those "others" we study and write about). Anthropology and ethnography have played an ambiguous historical role in the implementation of this value, and it is entirely appropriate that historians like Clifford should elucidate this role. Second, it is important to defend a plurality of voices in the academy. Venues like CURRENT ANTHROPOLOGY are premised on this value; in order to promote creativity and the possibility of improvement, authoritarian entrenchment of orthodoxies must be prevented.

In this regard, as Roth points out, Clifford has mixed feelings. Of course, Clifford does not dispute academic pluralism, but he nonetheless indulges in frequent prescriptive assertions regarding the "necessity" of accepting the superiority of his own "paradigm" (e.g., I983: I19, I33; I986b: I09, cited by Roth). I assume that he makes such assertions in the spirit of offering his own voice to the intersubjective context of academic dialog rather than that he intends them to dominate this context. Yet his suggestion that assumption of authorial voice in ethnographic writing constitutes a form of political domination makes exactly this latter unwarranted assumption about many of the texts he analyzes.

The point here is that in a third relevant context, that constituted by an argument or ethnography, the idea that there ought to be a plurality of voices (or a simulation of one) is both impractical (witness Clifford's own authorial voice) and detrimental to the implementation of pluralism in the political contexts of the academy and the wider social world. If it is to be contestable-i.e., if it is to grant legitimacy to the voices of those who disagree-an argument or ethnographic description cannot explicitly eschew totalizing coherence on the grounds that all truths are partial (Sangren 1988). This confusion thus allows Clifford to have things both ways. Those who would dispute his "paradigm" (loosely characterized as "discursive," "dialogic," "polyphonic" [I983: I33l) are caught in a double bind; because practical exercise of pluralistic disagreement would require epistemological "totalizing," inevitably the construction of a single authorial voice, it can easily be dismissed as either ( $\mathrm{I}$ ) a misguided expression of a will to dominate or (2) merely another in the plurality of voices possessing no intrinsic right to contest the logic or legitimacy of any other opinion. At the same time, the legitimacy of political pluralism in social and academic contexts is deployed inappropriately to the context of Clifford's own theorizing. By characterizing social reality as constituted by an aggregation of partial truths, Clifford makes a substantive claim at a high level of abstraction about the nature of social reality but draws upon the rhetorical value of pluralism in less abstract political contexts to the political effect of denying epistemological legitimacy to voices that would dispute the coherence of his characterizations.

In this regard, as Roth points out, Clifford's employment of the notion of the partiality of truth begs the question of misrepresentation, alienation, mystification, and ideology. That anthropologists, in constructing their ethnographic accounts, inevitably imply that they know something that the objects of these analyses do not is acutely embarrassing to those for whom culture is an autonomous symbolic system intelligible only in the (perhaps roughly "translatable") terms in which it represents itself. Clifford seems to see this problem as intractable; the solution is to eschew privileging of any voice or perspective and, in effect, abandon social theory. In the apocalyptic rhetoric of postmodernism, Clifford is a harbinger of the end of anthropology. The alternative to this pessimistic conclusion is to recognize a fundamental discontinuity between phenomenological reality and social reality. Much of the most promising theoretical work, in my view, is engaged in accounting for the structural characteristics of this discontinuity and for its dialectical mediation in social processes. Always contestable, the results of such efforts do not deny their own "partiality," but if they are to make sense and to be contestable they cannot eschew analytical authority (and responsibility) within the context of an argument.

\section{DAVID SAPIRE}

Philosophy Department, University of the

Witwatersrand, P.O. Wits 2050, Johannesburg, South Africa. I 3 vi 89

One of the things anthropologists do is write. Another thing they sometimes do is argue fallaciously from analogy, especially when the analogy concerned is broadly linguistic in nature. I find Roth's arguments welldirected and sound and think that the remarks just made help provide further support for his conclusions.

A language::culture analogy was influential in the 
early years of cultural anthropology. It was held that language is a part of culture and that, as things are in language, so they are in culture. Despite some merits, this reasoning abetted the ascription to cultures of properties at best possessed by languages (see, e.g., Aberle I960). More recently a variation of the theme emerged with the phoneme::language and phoneme::sociocultural phenomenon analogies underlying structuralism. Theorists who found these garbled but still sought broadly linguistic guidance, and others who sought more of it, could then turn to the text::culture analogy of Geertzian interpretation. One problem here, however, is that basic notions applicable to texts become "most elusive" when applied to cultural phenomena in general (Geertz 1980:177). Furthermore, mistakes about the leading notion of meaning become likely; the text::culture analogy encourages one to gloss the fact that cultural phenomena in general do not have meanings in quite the same way as words, sentences, paragraphs, and so on. In the most recent approach, analyzed by Roth, the theme undergoes yet another variation, for this is anthropology gone a little reflexive; it aims to reflect its own origins. The root idea now is a reflexive version of the text::culture analogy: writing a text::studying a culture, or writing::anthropology. Fictional rather than factual writing dominates the conception of the basic analogues. In addition, recourse is had to speech or dialogue as a crucial part of ethnography-dialogue::ethnography. Once again properties of broadly linguistic parts are used to illuminate wholes, and once again there is the danger of analogy-induced errors.

Two of the three confusions located by Roth seem to me to be of just this type. The first is the confusion of the stylistic devices that make a work of fiction plausible with the epistemological principles of justification or warrant. Since the distinction between these is clear enough, it is puzzling how the confusion can arise. But if literary composition holds the key to the full nature of anthropology, then the distinction falls away and there is no confusion. Warrant, justification, proof, and the like become plausibility or convincingness. We can create the world just by writing well enough.

With the confusion of political with epistemological representativeness, the real villain, as Roth notes, is political domination. But how can the depiction of ethnographers and those they study as equals in dialogue promote political equality? On an extreme interpretation (which I do not attribute to any writer in particular), if "fieldwork-based anthropology ... constructs and reconstructs coherent cultural others and interpreting selves" (Clifford I988:I I2) just as a writer creates fictional characters, or if ethnographic writings are fictions not only in that they are made or fashioned but also in that they invent things "not actually real" /Clifford I986:6) then to be is to be written about, and to be subordinate or equal is to be written about as subordinate or equal. We can create a morally acceptable world just by writing appropriately.

Glossing or ignoring false analogy leads to epistemological confusion, and this in turn leads to an ex- treme metaphysical anti-realism that places us all on a par with Noddy. But no matter how thoroughgoing a metaphysical anti-realism may be, it will be a nonstarter unless it allows for some metaphysical difference between everyday and fictional entities.

My only negative comment on Roth's paper itself is that I would have liked more from it on the metaphysical issues. Doesn't avoidance of the epistemological confusions involve the acceptance of a good measure of realism-in order to distinguish everyday from fictional characters, for instance? More generally, I think it is time for a very critical approach to analogies. In good factual thought or writing, analogies serve either as illustrations of or as aids to the discovery of literal truths, not as substitutes for them.

By revealing central shortcomings of the reflexive textual approach, Roth helps clarify where it might usefully contribute: not so much to epistemology or metaphysics as to our theories about the origin or development of anthropological theories. Attention to more than just writing would be necessary here, but whatever literal truths were forthcoming would be important and ultimately anthropological truths.

\section{MARILYN STRATHERN}

Department of Social Anthropology, Manchester

University, Manchester MI3 9PL, England. I3 vi 89

I find myself in sympathy with many of Roth's acute observations-of dialogic presentations not revealing what they presuppose, of stylised self-reflection no more guaranteeing authenticity than a pose of detachment, and of the way "experience" is used authoritatively. The problem is, to speak, not how one cries but how one writes about it afterwards. But I have a query about his claim that the present criticism generates no epistemological insights. It is important, I think, not to lose hold of one thing: that the scholars who have invested in the "union of epistemology and literary criticism" are in fact accomplishing an ethnography of our own times. Their work is "real," not, as Roth seems to imply, unreal. They are pressing into practice certain contemporary cultural suppositions that in calling for change (overthrowing discarded "paradigms," etc.) are in fact informative about cultural change. Since cultural change-whether Nuer or Ilongot or Californian-remains undertheorised in ethnographic science, I prefer to go on listening.

A further comment is in order, then, as to why Roth can "see" no epistemological insights. I am curious that of all the pieces he could have taken as the focus of his essay it should have been Rosaldo's (and, by implication, Danforth's that follows) "exercise in the new authorcentered ethnography." A couple of paragraphs earlier he cites Clifford's remark that paradigms of experience are yielding to paradigms of discourse and polyphony. Clearly, his and Clifford's characterisations of Rosaldo's intent are at odds here.

As I understand at least one strand of the new posi- 
tion, the "self" in (self-) reflexivity is not a person. It is an artefact-the ethnography. The questions that Clifford and others pose are about the making of the artefact; "voice" is a metaphor not for the individual subject (the ethnographer) but for how what is spoken sounds and is heard (the ethnography) or how what is made apparent is to be seen. If one attends to the author it is because there is more to the production of artefacts such as ethnographic texts than the illusion of the transparent writer allows. So to characterise the "new ethnography" as "author-centered" simply brings us back to the old position of "interpretation." The point is surely not that the author is re-centered but that the author is made visible. $\mathrm{He}$ or she can only be made visible, of course, by devices other than his or her own centering perspective.

It is confusing, irritating, and intriguing that critics of the new position seem to recreate two diametrically opposed positions themselves. They regard the new ethnography (or prescriptions for it) either as grossly decentered, taking away the intentions of the author, or as overly centered, as in the present account, which claims that "conventions emphasizing the sensitivity of the investigator serve as a litmus test for the authenticity of the account ${ }^{\prime \prime}-$ a curious appeal to authenticity when authenticity is part of the problem. To put it most crudely, these opposing positions together reinstate the very distance between subject and object, author and text, that at least some postmodernist productions attempt to overcome.

Contrary to the impression that Roth gives, there is a theory of culture at issue here: the insight we gain is into the production of artefacts. The knowledge that in the case of ethnographies we are dealing with artefacts that engineer perspectives of particular kinds is, I would have thought, knowledge worth gaining. One might therefore counter Roth's closing remark with the observation that if a "choice" of analytical or theoretical perspectives in anthropology is to be mediated through ethnography at all, then it can hardly be free choice.

STEPHEN A. TYLER

Department of Anthropology, Rice University, P.O.

Box I892, Houston, Tex. 7725I, U.S.A. 23 v 89

The point is not "what counts as a reliable representation of experiences and cultures" or "a problem of anthropological knowledge" or "the warrant for ethnographic claims" or "how properly to warrant claims," and the critical issues are not "authenticity," "data," "proof," "truth" (partial or impartial), "reflexivity," "reflecting," "revealing," or "the self" (objective, subjective, intersubjective) or, finally, even a matter of texts and textualization. The point is the irrelevance of these issues-these concerns and concepts that make the unreal discourse of the real.

What founds this funny, self-confirming rhetoric of "representation," "knowledge," "warrant," "proof," "evidence," "data"? What warrants the hegemonic claim of these concepts, legitimates their rhetoric as nonrhetoric, and enables them to arrest discourses that jump claims? What "representation," "knowledge," "proof," "data," "truth" "reflects," "describes," "warrants," and "legitimizes their "reflexive" "authentication"? Where here is the separation of politics and epistemology, the representation "in a political sense" that is not already an epistemology of representation-an epistopolitics? Where now is the possibility of "authority," "authenticity," "truth," "proof," "data," when all representation has become presentation?

Roth is right, polyphonic and dialogic texts are not better representations, but his mistake is in thinking that they are representations at all and could therefore be evaluated in the rhetoric of representation. Representation is not what they're about. They defy the ontic irresponsibility of the rhetoric of that mimetic mode and reckon differently.

The "de-" of "de-scription" tells the tale. It no longer matters how we write, because the book is obsolete, and that is why we can now afford to worry about how we write. The book is dying out (proved, as the population people like to say, by its excessive proliferation) and with it the rhetoric of the book and the language of writing, too. In place of the book, we have the "becomingtext," an endless textualizing that never quite becomes a book or, if it does, is passé or, even worse, "popular." No real scientist writes more than multiauthored abstracts of papers published "by title only," or perhaps a research application, and psychologists, emulating, as usual, a dead custom in physics, write only articles. In academia, illiteracy is a sign of high status and scientific rectitude. So, it's best to give up on writing altogether. Even handouts are out, and overhead projectors may be OK for psychologists, but to do it right, networking's the thing!

\section{Reply}

PAUL A. ROTH

St. Louis, Mo. 63 I2 I, U.S.A. 3 I viI 89

Clifford's concern with the nature and the source of the authority imputed to ethnographic claims is what, in my view, makes his work an exercise in the epistemology of ethnographies; his way of linking authority and authors is what makes it bad epistemology. He strongly denies that this is how he is to be read. I would hope that he and I are not doomed continually to talk past one another, but his comments do not make me optimistic. Perhaps part of the problem lies in our attaching different meanings to the term "authority." My complaint concerns his way of linking authorial self-presentation and the credibility-my gloss on "authority" - which allegedly attaches to characterizations and claims on the basis of this linkage. I think he assumes that authorial selfpresentation is what determines the standing of claims in a text. Thus, in his writings, analyses of narrative 
voice characteristically are substituted for analyses of arguments or of theoretical positions.

Limning the basic presuppositions of a position, exploring what gets counted in or counted out given those presuppositions, examining how conclusions are drawn within a particular framework, etc., are all part of epistemological inquiry. In this regard, epistemology constitutes a form of critique. Given the way in which this critique has operated in and informed on the philosophy of science and of social science, especially with regard to claims of objectivity, modes of constituting facts, etc., Clifford's insistence that locating positions in a certain historical and political context is not an aspect of epistemology surprises me. What would he call it? The issue between us, I would have said, is how critique is best and most properly pursued.

I am not alone in reading Clifford as I do. Of course, this is no proof that I am correct; it is evidence, however, that he needs to do more than juxtapose his essays in a particular way to forestall certain misunderstandings.

Perhaps a major difference between my slant on matters and Clifford's is that I am uncertain, pending closer analysis, how the intentions, backgrounds, and other characteristics of ethnographers determine what is right or wrong about the ethnographies they produce. Clifford is, as I read him, so taken with the conventionality of the processes he studies that he neglects to ask how adopting a particular methodological approach might illuminate the subject matter.

A major motivation for pluralism, at least in my own case, is an appreciation of how different social theories enlighten. But a pluralist like myself is also a skeptic; no one perspective is privileged, even though some are demonstrably better or worse. This position has its near relations in the sort of pragmatism about inquiry that Rorty (1979) advocates and in Carnap's (I 947) distinction between internal and external questions. Choice of methodological approaches, Carnap maintained, is dictated by pragmatic considerations. "Which method should I use?" is, in Carnap's terminology, an external question. Such questions have no absolute right or wrong answers; there is only the issue of which approach best serves one's interests. Once one adopts a particular theoretical approach, however, questions of right and wrong are meaningful, inasmuch as these matters can be adjudicated within one's chosen framework. I would add that methods can be evaluated in terms of their relative fruitfulness, problem-solving power, and simplicity. These external criteria, however, should not be expected to suffice to make just one approach attractive or viable. This will not satisfy those more certain than I that they know where the truth lies on all matters social. Both Herzfeld and Sangren offer apt comments on pluralism and its politics.

There is a confrontation, most evident in the pages of Social Studies of Science, between those (such as Bruno Latour and Steve Woolgar) who advocate a constructivist view of the social and the scientific without attempting to explain these constructions by appeal to, for example, social interests and those (such as Barry Barnes, Harry
Collins, and Andrew Pickering/ who believe that social interests are what explain the shape the world takes within science and without. These debates concern issues that could rightly be termed, to borrow Tyler's coinage, "epistopolitics." As my references to Woolgar's work suggest, I share his skepticism regarding the efficacy of interest explanations.

Unlike Tyler, I do not consider it epistemological or political bad faith to entertain at least an analytic separation of the epistemological and the political. What makes discussions of authority, truth, etc., possible is adoption of a social theory. Acknowledging that these terms are theoretically circumscribed does not render them illegitimate or useless. Perhaps Tyler is persuaded that if there is no transcendent perspective, all the terms he has in quotation marks cease to be worth discussing, but that conclusion is surely too extreme. One may despair of claims to absolute truth and still believe that it is possible to learn. I hesitate about exactly what to impute to Tyler, however, for some of his remarks are playful and I am unsure that I always catch the spirit of his play.

Strathern and Herzfeld raise related serious and thoughtful objections. In particular, both worry that I hold that textual considerations are epistemologically irrelevant. This is not my view; what is at issue, I would again emphasize, is how this relevance is best examined and understood. In this regard, I did not wish to imply that Rosaldo's worry regarding positioning lacked a point. Clearly, how one is positioned, in Rosaldo's sense, is of epistemological moment. I cited that instance to illustrate the sort of blindness against which it is impossible to guard in these (and all related) matters. My complaint, rather, is against the assumption that some pose or perspective is a guarantee against such failures of insight. In particular, protestations of sincerity and deep feeling do not serve as a methodological solvent by which to eradicate culturally or theoretically induced failures of insight. Herzfeld worries that I would indiscriminately cast all lamenters into the pit. What I say of Rosaldo and Danforth, however, is not that they fail as ethnographers but that their tears and other stylized protestations of fellow feeling are not germane to the doing or the evaluating of ethnography. And on this point, I take it, Strathern, Herzfeld, and I agree.

Strathern's remarks make clear that my choice of examples is not always consonant with the issues I discuss. She notes, in addition, that those who catalog textual strategies are engaged in "an ethnography of our own times." At best, that is what is going on; nonetheless, an anthropological analog to Hayden White's Metahistory remains to be written. I disagree with Strathern regarding the significance of current strategies to "make the author visible"; my concern is with fruitful modes of constructing critiques. The problem is not how to expose the "illusion of the transparent writer," or not just that, anyway. She is correct to insist that the fact that ethnographies engineer perspective is knowledge worth having, but critique demands that we know much more than this. We have gained some awareness 
of the conventions of authorial presentation and so of the deliberate constructedness of ethnographies qua cultural artifacts. This is the genuine achievement of Clifford's work. However, the linkages between ethnographic representation, ethnographic rationalizations, and the politics of ethnography remain to be traced. Finally, I agree with Strathern that appeals to authenticity are part of the problem, but I am puzzled that she implicates me in such appeals. Perhaps I did not make explicit enough that I regard the very notion of "authenticity" as bogus, at least as an analytic construct or explanatory category. Herzfeld, in this regard, takes his initial discussions of pluralism, empirical adequacy, and authenticity in directions I find congenial. I am not sure that I understand his brief apologia for tears, and whether the comparativist project holds the promise he finds in it remains to be seen.

Sapire raises a fundamental question with regard to a type of antirealism that perhaps I share with those whom I criticize: the assumption that there is no cultural "fact of the matter," that there is only an imposition or illusion of coherence that is a product of the writing about it. Sapire counters this antirealism with the intuitively appealing and commonsensical query whether it is plausible that to be is to be written about. In addition, he is willing to countenance the existence of distinctively anthropological truths, though he refrains from specifying in what vocabulary these truths are to be couched. Sapire's realist intuitions and my own pluralist proclivities sharply diverge with respect to these issues, but this is not the place to debate the matter. The rationales for my generally antirealist view on interpretive matters are in Roth (1987). What is worth noting, and this is an insight I owe to Sapire's way of formulating the issues, is that, realism or antirealism notwithstanding, I differ radically from those whom I criticize in views of how empirical evidence weighs in when one is evaluating claims. Sapire wonders, rightly, how a confusion of the literary and the epistemological might have occurred; his insightful suggestion is that it presupposes that issues of literary composition hold the "key to the full nature of anthropology." Despite my high regard for the work of Clifford's colleague Hayden White and my conviction, following White, that there are multiple ways to emplot any set of facts, the emphasis on literariness is, in the current anthropological debate, misplaced. It is misplaced, ultimately, because issues are tied not, as in White's analyses, to the internal logic and formal constraints of modes of representation but only to the image of the author.

Buchowski's "view from afar" speaks to a concern near to the heart of my essay. Both of us believe that it is possible to preserve some account of scientific reasoning-meaning, at a minimum, the making of empirically grounded claims subject to some general canon of confirmation or falsification-even in the face of the conventionality and other acknowledged limits of theoretical approaches. Einstein is supposed to have remarked that it is not the purpose of science to give one the taste of the soup. Likewise, ethnography that does not take as its exclusive, or even primary, concern local knowledge is not, for that reason alone, to be condemned. At the other extreme, as Buchowski notes, emphasis on the ethnographically ephemeral must erode anthropology as a discipline, for whatever is supposed to be disciplined about such studies threatens to disappear beneath the avalanche of concern regarding the constructedness of it all.

Sangren broaches issues that call for discussion but are difficult to articulate in a helpful way, including who is represented and how, whose voice is heard and where, whose agenda is adopted and whose marginalized. Everyone involved in these debates, I assume, worries deeply about these questions. Clifford's charge that I seek to avoid them is only a symptom of how deep the differences between us are regarding (I) how best best to confront issues of power and domination and (2) how best to challenge assumptions that we take to be not just wrong-headed but dangerous and hurtful.

Demands that declarations of political orientation accompany one's work I put in the same category with calls for loyalty oaths and declarations of faith. Like Sangren, I find much of the methodological debate that goes under the name of postmodernism regressive rather than progressive on just this point of elucidating the relation of politics and epistemology. As Rorty has noted, in a pejorative and discredited sense of the term "epistemology" connotes a belief in a neutral matrix suitable for rationally evaluating all claims in any area. It is, however, a mistake to think that rational discourse is impossible without that neutral matrix. The choice of vocabulary becomes, as Rorty argues, a moral choice. Buchowski, Sangren, and I take it to be both possible and appropriate to separate the personal and the epistemological; authors are not the source of or to be identified with textual authority, at least in nonfictional discourse. The realization that there is no neutral matrix of discourse encourages a hermeneutics of suspicion; it is not a license to reject theories because of the sins of their authors.

\section{References Cited}

ABERLE, DAVID F. I960. "The influence of linguistics on early culture and personality theory," in Essays in the science of culture. Edited by G. E. Dole and R. L. Carneiro, pp. I-29. New York: Thomas Crowell. [DS]

ASAD, TALAL. Editor. I973. Anthropology and the colonial encounter. New York: Humanities Press.

BARNES, BARRY, AND DAVID BLOOR. I982. "Relativism, rationalism, and the sociology of knowledge," in Rationality and relativism. Edited by $M$. Hollis and S. Lukes. Cambridge: M.I.T. Press.

BEIDELMAN, THOMAS O. I980. The moral imagination of the Kaguru: Some thoughts on tricksters, translation, and comparative analysis. American Ethnologist 7:27-42. [MH]

BOON, JAMES A. I980. Comparative de-enlightenment: Paradox and limits in the history of ethnology. Daedalus ro9 (Spring), pp. 73-9I.

I982. Other tribes, other scribes: Symbolic anthropology in the comparative study of cultures, histories, religions, and texts. Cambridge: Cambridge University Press. 
CARNAP, RUDOLF. I947. Meaning and necessity. Chicago: University of Chicago Press.

CLIFFORD, JAMES. I980. Fieldwork, reciprocity, and the making of ethnographic texts: The example of Maurice Leenhardt. Man I 5:518-32.

I983. On ethnographic authority. Representations I: I I 8-46. I986a. "Introduction: Partial truths," in Writing culture.

Edited by J. Clifford and G. E. Marcus, pp. I-26. Berkeley: University of California Press.

r I986b. "On ethnographic allegory," in Writing culture.

Edited by J. Clifford and G. E. Marcus, pp. 98-I2I. Berkeley: University of California Press.

. I 988. The predicament of culture. Cambridge: Harvard University Press.

CLIFFORD, JAMES, AND GEORGE MARCUS. Editors. I986. Writing culture: The poetics and politics of ethnography. Berkeley: University of California Press. [MH]

CRAPANZANO, v. I986. "Hermes' dilemma: The masking of subversion in ethnographic description," in Writing culture. Edited by J. Clifford and G. E. Marcus, pp. 51-76. Berkeley: University of California Press.

DANFORTH, LORING. I982. The death rituals of rural Greece. Princeton: Princeton University Press.

DUMONT, LOUIS. I982. On value. London: Oxford University Press. [MH]

ELSHTAIN, JEAN BETHKE. I987. "Feminist political rhetoric and women's studies," in Rhetoric of the human sciences. Edited by John Nelson, A. Megill, and D. McCloskey. Madison: University of Wisconsin Press.

FABIAN, JOHANNES. I983. Time and the other: How anthropology makes its object. New York: Columbia University Press. [MH]

FISCHER, MICHAEL M. J. I986. "Ethnicity and the post-modern arts of memory," in Writing culture. Edited by J. Clifford and G. E. Marcus, pp. 244-47. Berkeley: University of California Press.

FORMAN, PAUL. I97I. "Weimar culture, quantum theory, and causality, 1918-1927: Adaptation by German physicists and mathematicians to a hostile environment," in Historical studies in the physical sciences, vol. 3. Edited by R. McCormmach. Philadelphia: University of Pennsylvania Press.

FRIEDRICH, PAUL. I989. Multiplicity and pluralism in anthropological construction/synthesis. Anthropological Quarterly 6I:IO3-I2. [MH]

GARFINKEL, HAROLD. I967. Studies in ethnomethodology. Englewood Cliffs: Prentice-Hall.

GEERTZ, CLIFFORD. I979a. "From the native's point of view: On the nature of anthropological understanding," in Interpretive social science: $A$ reader. Edited by P. Rabinow and W. Sullivan. Berkeley: University of California Press.

. I $979 b$. "Deep play: Notes on a Balinese cockfight," in Interpretive social science: $A$ reader. Edited by P. Rabinow and W. Sullivan. Berkeley: University of California Press.

. I980. Blurred genres: The refiguration of social thought. American Scholar 29:165-79.

- I985. Waddling in. Times Literary Supplement, June 7, pp. $623-24$.

. I988. Work and lives: The anthropologist as author. Stanford: Stanford University Press.

GORDON, DEBORAH. I988. Writing culture, writing feminism: The poetics and politics of experimental ethnography. Inscriptions 3/4:7-24. [JC]

HANDLER, RICHARD. I986. Authenticity. Anthropology Today $2(\mathrm{I}): 2-4$. [MH]

HERZFELD, MICHAE L. I987. Anthropology through the lookingglass: Critical ethnography in the margins of Europe. Cambridge: Cambridge University Press. [ $\mathrm{MH}]$

HOLLIS, M., AND S. LUKES. Editors. 1982. Rationality and relativism. Cambridge: M.I.T. Press.

HOOKS, B ELL. I989. Expertease. Art Forum. May, pp. I8-20. [JC]

KEESING, ROGER M. I987. Anthropology as interpretive quest. CURRENT ANTHROPOLOGY 28:16I-76.

LATOUR, B., AND S. WOOLGAR. I986. 2 d edition. Laboratory life: The construction of scientific facts. Princeton: Princeton University Press.
MAQUET, JACQUES J. I964. Objectivity in anthropology. CURRENT ANTHROPOLOGY 5:47-55.

MARCUS, GEORGE E. I986. "Contemporary problems of ethnography in the modern world system," in Writing culture. Edited by J. Clifford and G. E. Marcus, pp. 165-93. Berkeley: University of California Press.

MARCUS, GEORGE E., AND DICK CUSHMAN. I982. Ethnographies as texts. Annual Review of Anthropology I I:25-69.

MARTIN, WALLACE. 1986. Recent theories of narrative. Ithaca: Cornell University Press.

NEEDHAM, RODNEY. I980. Belief, language, and experience. Oxford: Basil Blackwell. ]MH].

PICKERING, ANDREW. I984. Constructing quarks: A sociological history of particle physics. Chicago: University of Chicago Press.

PRATT, MARY LOUISE. I986. "Fieldwork in common places," in Writing culture. Edited by J. Clifford and G. Marcus, pp. 27-50. Berkeley: University of California Press. [JC]

RABINOW, PAUL. 1977. Reflections on fieldwork in Morocco. Berkeley: University of California Press.

- I983. "Facts are a word of God: An essay review of James Clifford's Person and myth: Maurice Leenhardt in the Melanesian world [Berkeley: University of California Press, I982]," in Observers observed. Edited by G. W. Stocking. Madison: University of Wisconsin Press.

. I986. "Representations are social facts: Modernity and post-modernity in anthropology," in Writing culture. Edited by J. Clifford and G. E. Marcus, pp. I94-233. Berkeley: University of California.

RORTY, RICHARD. I979. Philosophy and the mirror of nature. Princeton: Princeton University Press.

ROSALDO, RENATO. I980. Ilongot headhunting 1883-1974: A study in society and history. Stanford: Stanford University Press. [MH]

- I984. "Grief and a headhunter's rage: On the cultural force of emotions," in Text, play, and story: The construction and reconstruction of self and society. Edited by E. M. Bruner, pp. 178-95. Washington, D.C.: American Ethnological Society.

. I989. Culture and truth: The remaking of social analysis. Boston: Beacon Press. [MH]

ROTH, PAUL A. I987. Meaning and method in the social sciences: $A$ case for methodological pluralism. Ithaca: Cornell University Press.

SANGREN, P. STEVEN. I988. Rhetoric and the authority of ethnography: "Postmodernism" and the social reproduction of texts. CURRENT ANTHROPOLOGY 29:405-35.

SCHWIMMER, ERIK. I979. Reciprocity and structure: A semiotic analysis of some Orokaiva exchange data. Man I 4:27 I-85. [MH]

STRATHERN, MARILYN. I987. Out of context: The persuasive fictions of anthropology. CURRENT ANTHROPOLOGY 28:25 I-8I.

TYLER, STEPHEN A. I986. "Post-modern ethnography: From document of the occult to occult document," in Writing culture. Edited by J. Clifford and G. E. Marcus, pp. I22-40. Berkeley: University of California Press.

VAN MAANEN, JOHN. I988. Tales of the field: On writing ethnography. Chicago: University of Chicago Press.

WINCH, PETER. I970. "Understanding a primitive society," in Rationality. Edited by Bryan Wilson, pp. 78-I I I. London: Basil Blackwell.

- 1977. "Understanding a primitive society," in Understanding and social inquiry. Edited by F. Dallmayr and T. McCarthy. Notre Dame: Notre Dame University Press.

WOOLGAR, STEVE. I 98 I $a$. Interests and explanation in the social study of science. Social Studies of Science I I:365-94. . I $98 \mathrm{I} b$. Critique and criticism: Two readings of ethnomethodology. Social Studies of Science i I:504-I 4.
. I983. "Irony in the social study of science," in Science observed. Edited by K. Knorr-Cetina and M. Mulkay, pp. 23966. Beverly Hills: Sage.

. I988. Time and documents in researcher interaction: Some ways of making out what is happening in researcher interaction. Human Studies I I: I 7 I-200. 